\title{
Material Removal Rate and Tool Wear Rate on Machining of Inconel 718 using Electrical Discharge Machine
}

\author{
Boopathi $\mathbf{R}^{1 *}$, R Thanigaivelan ${ }^{1}, \mathbf{R}$ Prabu $^{1}$ and $\mathbf{M}$ Prabu $^{2}$ \\ ${ }^{1}$ Department of Mechanical Engineering, India \\ ${ }^{2}$ Department of Mechanical Engineering, India \\ *Corresponding author: Boopathi R, Department of Mechanical Engineering, Mallasamudram, India
}

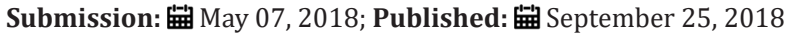

\begin{abstract}
Electrical discharge machining is a manufacturing process with a large industrial implementation. The addition of powder particles in suspension in the dielectric modifies some process variables and creates hard and brittle materials with nano surface finish, high tolerance and accuracy to achieve a material removal rate increase. This paper presents a research work to study the performance improvement of material removal rate (MRR) and tool wear rate (TWR)on the nano particle mixed electrical discharge machining. Work piece used is Inconel 718 and tool materials used brass electrode. The electrolyte used is kerosene oil. Titanium carbide nano particle is having high mechanical and electrical properties specifically high electrical conductivity. The input parameters like current, pulse on-time and pulse off-time and outputs MRR and TWR. The experiment results analysis titanium carbide nano particle mixed dielectric fluid to achieve maximum MRR and minimize TWR.
\end{abstract}

Keywords: TiC; EDM; MRR; TWR

\section{Introduction}

Electrical Discharge Machine (EDM) is a nontraditional machining process, where electrical energy is used to make electrical spark and material removal mainly occurs due to thermal energy of the spark. The latest concept of manufacturing uses unconventional energy source similar to sound, light, chemical, electrical, mechanical, electrons. With the industrial and scientific growth, development of harder and complicated to machine materials, which find broad application in nuclear, aerospace engineering and other industries due to their high strength to weight ratio, hardness and heat resistance character has been observer. Latest developments in the field of material science have led to new composite materials, engineering metallic materials and high-tech ceramics have high quality mechanical properties and thermal characteristics as fit as sufficient electrical conductivity so that they can gladly be machined by spark erosion [1]. Non-traditional machining has developed out of the need to machine these smart materials. The machining technique is non-traditional in the intellect that they do not utilize traditional tools for metal removal and instead they straight use other forms of energy. The problems of high complication in shape, size and higher demand for product precision and surface finish can be solve through non-traditional methods [2]. Currently, non-traditional process take nearly infinite capabilities except for volumetric material removal rates, for which vast precede have been made in the past few years to increase the material removal rates. As removal rate increases, the cost efficiency of operations also boost, motivating ever greater uses of non-traditional process. The electrical discharge machining process is working extensively for production dies, tools and new precision parts [3]. EDM has been replacing drilling, grinding, milling and other traditional machining operations and is now a well-established machining option in many manufacturing industries throughout the globe. With is capable of machining geometrically complex or hard material components, that are precise and not easy to machine such as heat treat tool steels, super alloys, ceramics, composites, carbides, heat resistant steels etc. Being generally used in die and mold making aerospace, aeronautics, industries and nuclear industries. Electrical discharge machining has also made its presence felt in the new fields such as sports, optical, medical and surgical, instruments, including automotive R\&D areas [4]. Powder mixed dielectric fluid in electrical discharge machining (PMEDM) is a comparatively latest advance material removal process useful to develop the machining efficiency and surface finish. Powder particles mixed dielectric medium the faster sparking and increase thermal conductivity within a discharge arise causing faster erosion from the workpiece surface and thus the material removal rate increases [5]. In nano sized powder, suspended $\mathrm{SiC}$ and $\mathrm{Al}_{2} \mathrm{O}_{3}$ in dielectric fluid will change the surface roughness. A powder suspended dielectric is among $14 \%$ and $24 \%$ of the average surface roughness generated. The addition of nano particle to a dielectric fluid has further benefit in improving 
surface quality by eliminating micro-cracks. Moreover, the suspension of nano graphite powder produced a high sparking gap size [6]. The carbon nano tube (CNT) is mixed with dielectric fluid in AISI D2 tool steel material is very good thermal conductivity, absorb heat and white layer creation is reduced and surface finish can be greater [7]. Inconel 718 has been preferred for the analysis because of its increasing demand in high temperature applications and lack of literature available on electrical discharge machining of this material. In the present paper, a challenge has been made to obtain an optimal setting of process parameters, which may yield optimum MRR and TWR.

\section{Literature Survey}

It is important to understand the history and current status of the EDM process to propose future areas of work. Extensive literature survey has been carried out to find the state of art at EDM process. Electrical discharge machining provides an efficient manufacturing technique that enables the production of parts made of hard materials with complicated geometry that are difficult to produce by conventional machining processes. Its facility to control the process parameters to achieve the required dimensional accuracy and surface finish has placed this machining operation in a prominent position in industrial applications [8]. Inconel 718 by creation deep hole drilling with EDM. The parameters current, pulse on time, pulse off time and electrode speed were select input parameters. The output responses were metal removal rate, depth of standard surface roughness [9]. The experimented were planned using central composite design. The results revealed that metal removal rate is more influenced by peak current, duty factor and electrode rotation, and MRR is increased with increase in current and duty factor and electrode speed, whereas depth of average surface roughness is increased with increase in peak current, electrode speed and pulse on-time [10-12]. Aluminium bronze machined with nickel powder mixed kerosene dielectric fluid has a smaller surface roughness than that in conventional EDM with pure kerosene. Recast layer restricted nickel very well and the thickness of white layer became larger and uniform with an increase in the concentration of nickel powder. Further, the hardness of the white layer is higher, and the surface is smoother than that with kerosene oil [11]. To improve surface roughness and reduce machining time and tool wear. For that they have used different powder like silicon, aluminiam, graphite and carbon nano tube mixed with dielectric fluid and experiment work on NAK 80 steel using copper electrode (Figure 1).

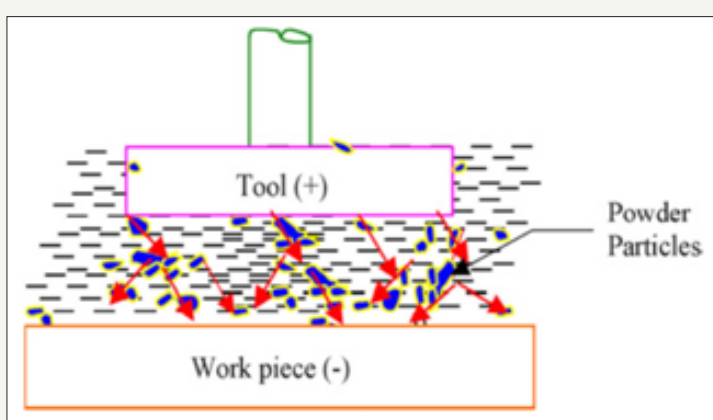

Figure 1: Principle of powder mixed EDM.
They contain analyses three different parameter like effect of various powders mixed into dielectric on surface roughness, machining time and on tool wear. They have done that development of the machining effectiveness and the roughness of a machined surface by adds carbon nano tube to the dielectric. The surface roughness of the work piece and the machining efficiency of the EDM with powder mixed into the dielectric were enhanced by $70 \%$ and $66 \%$ respectively, compared with conventional EDM. Carbon nano tubes show better attainment than other powder [13]. Nano surface finish has become an important parameter in the semiconductor, electrical and mechanical industries. The materials worn in this industry are secret as difficult to machine materials such as glasses, ceramics and silicon. Machining of these materials up to nano accuracy is a great challenge in the manufacturing industry. Final of micro components such as, micro moulds, micro lenses and micro holes require special processing techniques. Conventional finishing methods used so remote become roughly impossible. In this paper, a nano material especially multi wall carbon nano tube is worn in the machining process similar to grinding to improve the surface characteristics from micro to nano level [14].

\section{Experimental Procedure}

The equipment used to perform the experiments is a die sinking EDM (ELECTRONICA-M100 MODEL) machine. The selected work piece material is Inconel 718. The Inconel 718 is a high strength, temperature resistant (HSTR) nickel based super alloy. It is extensively used in aerospace applications such as gas turbines, rocket motors, space crafts, pumps and tooling. Inconel -718 is difficult to machine, of its poor thermal properties, high toughness, high hardness and high work hardening rate so machining conventional process is very difficult. The tool electrode material used is brass. The brass electrode be the negative polarity and the specimen was the positive polarity. The dielectric fluid was mixed in titanium carbide nano particle for kerosene. The separate tank was used for machining with using Titanium carbide nano particle mixed dielectric fluid. During EDM, the primary parameters are current, pulseon time, and pulse-off time. The machining was generally carried out for a fixed time interval and the amount of MRR and TWR was measured by taking the difference in weights before and after each experiment using an electric balance with a resolution of $0.001 \mathrm{mg}$ to determine the value of metal removal rate was measured from the weight loss.

\section{Experimental plan}

Response surface methodology (RSM) approach is the procedure for determining the relationship between various process parameters with the various machining criteria and exploring the effect of these process parameters on the coupled responses [15]. The MRR and TWR. In order to study the effect of the EDM parameters on the above mentioned two most criteria, a second order polynomial response can be fitted into the following equation

$$
Y_{u}=b_{o}+\sum_{i=1}^{k} b_{i} x_{i}+\sum_{i=1}^{k} b_{i} x_{i}^{2}+\sum_{j>1}^{k} b_{j} x_{i} x_{j}
$$


Where $\mathrm{YU}$ is response and the $\mathrm{x}_{\mathrm{i}}(1,2, \ldots . ., \mathrm{k})$ are coded level of $\mathrm{k}$ quantitative variables. The coefficient $b_{0}$ is the constant term, the coefficients bi are the linear terms, $b_{i \mathrm{i}}$ are the quadratic terms and $b_{i j}$ are the interaction terms. The relevant process parameter selected for the present investigation are current, pulse on-time and pulse off-time on the metal MRR and TWR during the EDM process. For the three variables the design required 20 experiments with 8 factorial points, 6 axial points to form face centered composite design with $\alpha=1$ and 6 centre points for replication to estimate the experimental error. The design was generated and analyzed using MINITAB 14.0 statistical package. The levels of each factor were chosen as $-1,0,1$, in closed form to have a rotatable design. The experiment has been carried out according to the central composite second order rotatable design.

\section{Mathematical modeling}

The relationship between the factors and the performance measure was modeled by multiple linear regressions. Mathematical models based on second-order polynomial equations were developed for MRR and TWR using the experimental results and are as follows:

$\mathrm{MRR}=0.028100-0.000505 \mathrm{~A}+0.000020 \mathrm{~B}-0.000264$ $\mathrm{C}+0.000286 \mathrm{~A} 2+0.000001 \mathrm{C} 2-0.000010 \mathrm{~A}^{*} \mathrm{C}(2)$

TWR $=0.009787+0.004242 \mathrm{~A}+0.000007 \mathrm{~B}-0.000186$ C-0.000113 A2-0.000001 A*B-0.000002A*C (3)

\section{Results and Discussion}

The parametric analysis has been carried out to study the influences of the input process parameters such as current, pulse ontime and pulse off-time on the process responses, such as MRR and surface roughness during EDM die-sinking process. The influences of the current and pulse on-time on MRR are shown in Figure 2. It can observe that with the increase in current and degrease pulse on-time. The MRR is directly proportional to the amount of energy applied during this on-time as degrease in pulse-on time slightly increases MRR values. These factors result in higher thermal loading on both electrodes (tool and work piece) followed by higher amount of material being removed.

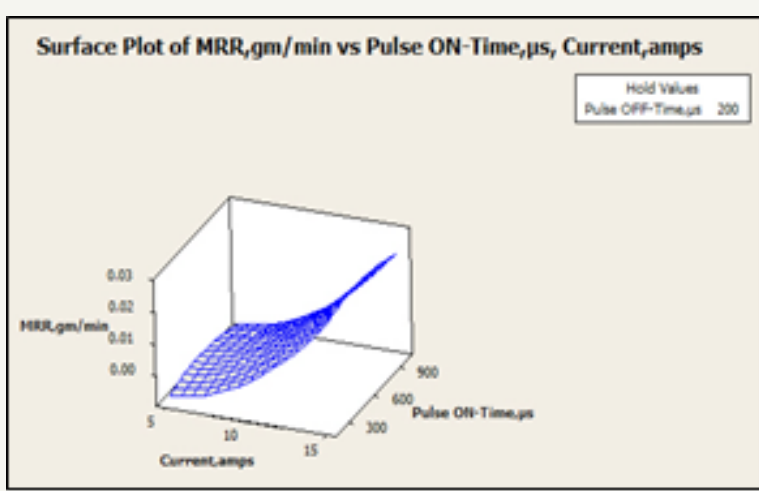

Figure 2: Influence of current and pulse On-time on MRR.

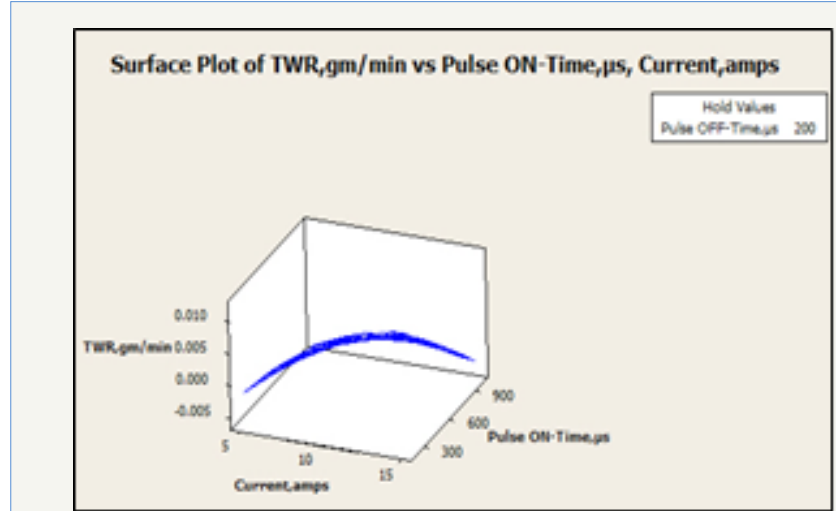

Figure 3: Influence of pulse on-time and pulse off-time on MRR.

The influences of the pulse on-time and pulse off-time on MRR are shown in Figure 3. The variation of MRR with pulse on-time and pulse off time is discussed here. Increase in the pulse on-time and time leads to increase in MRR. This result in higher thermal loading on both electrodes due to material being removed. And also increasing in off-time, the MRR is parabolic shape with increasing slope with increase in off time, and at certain optimum level the MRR shows a decreasing. The slope decreases with increasing pulse duration, resulting in increase in MRR.

The influences of the current and pulse on-time on TWR are shown in Figure 4. It can be concluded that TWR increases proportionally with increase in on-time and current values. It can be noted that the TWR is increasing with increase in pulse on-time however the TWR decreases with increase in current. The reasons being due to increase in current, spark energy increases and due to this a larger but shallower crater are formed at higher current values due to expansion of the plasma channel in the discharge gap. The influences of the pulse on-time and pulse off-time on TWR are shown in Figure 5. TWR increases with an increase in the pulse on-time. It is because increase in the pulse off-time, inter-electrode gap becomes smaller. This, in turn, causes a reduction of the electric resistance of the electrolyte and is increases the current density and then TWR. Pulse on-time in the low range in degrease TWR, whereas high TWR results when the Pulse on-time. The reasons for the substantial decrease in TWR.

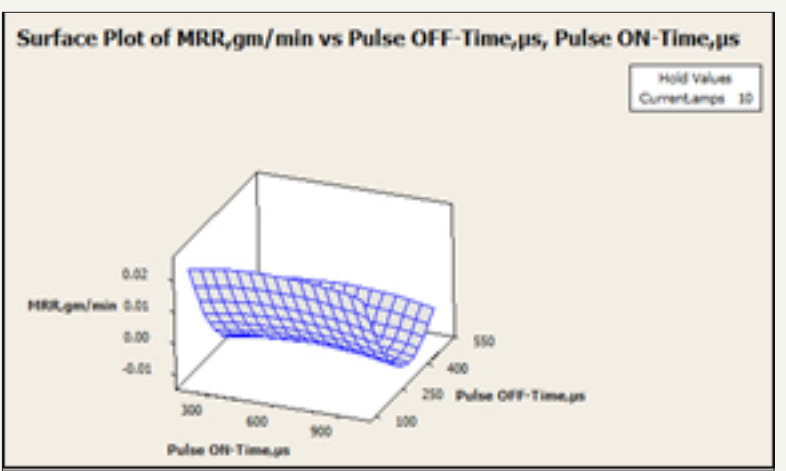

Figure 4: Influence of current and pulse on-time on TWR. 


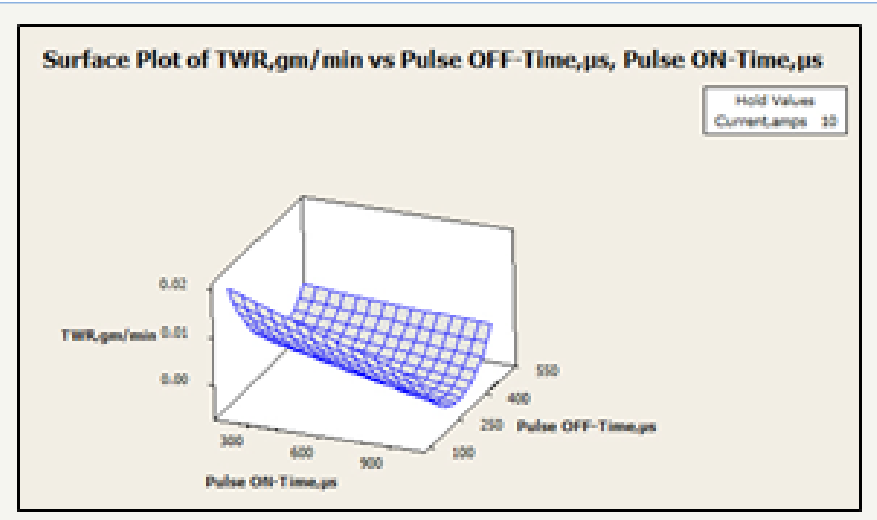

Figure 5: Influence of pulse on-time and pulse off-time on TWR.

\section{Conclusion}

Inconel 718 can be machined by EDM with titanium carbide nano particle was suspended into the kerosene as a dielectric fluid and a better rate of MRR and lower TWR has been achieved. Mathematical modeling with the help of RSM has lead to the following conclusions about the variation of response parameters in terms of independent parameters within the specified range. From the analysis, the following conclusions are drawn:

A. With increase in current and MRR increases.

B. The pulse on-time has direct effect on the MRR, as increase the pulse on-time the MRR also increases.

C. With increase in current and pulse on-time, the spark discharge energy is increased to facilitate the action of melting and vaporization and advancing the large impulsive force in the spark gap, thereby increasing the MRR.

D. When the pulse off- time is increased the MRR decreases.

E. Increasing in the discharge current $5 \mathrm{~A}$ the TWR is decreasing, but discharge current in the range of $10 \mathrm{~A}$ to $15 \mathrm{~A}$ the TWR is increasing.

F. Because of pulse on-time increases the energy hence more heat energy is produced in the tool work piece interface, leads to increase the melting and evaporation of the electrode.

G. It is observed that with an increase in discharge current, TWR increases.

H. This causes more and more erosion of tool material with increase in current.
The pulse on is increasing the TWR is increasing, at minimum pulse on minimum TWR.

\section{References}

1. Boopathi R, Sundaram S, Senthilkumar C, Prabu M (2017) Effect of machining characteristics of nano-TiC mixed dielectric fluids on Inconel 718 in the EDM process. Mat Testing 59 (4): 402-408.

2. Liao YS, Huang JT, Su HC (1997) A study on the machining-parameters optimization of wire electrical discharge machining. J Mat Pro Tech 72 (1): 487-493.

3. Boopathi R, Sundaram S, Senthilkumar C, Prabu M (2015) Multiobjective optimization of nanoparticles mixed electrical discharge machining of Inconel 718. Inter J App Engg Res 10(8): 5976-5979.

4. Boopathi R, Thanigaivelan R, Prabu M (2018) Effects of process parameters on MRR, EWR and Ra in nanoparticles Mixed EDM. Research \& Develop Mat Sci 4(3): 1-3.

5. Kuldeep 0, Garg RK, Singh RK (2011) Experimental investigation and modeling of PMEDM process with chromium powder suspended dielectric. Int J Appl Sci Engg 9(2): 65-81.

6. Prihandana GS, Mahardika M, Hamdi M, Wong YS, Mitsui K (2011) Accuracy improvement in nanographite powder-suspended dielectric fluid for micro-electrical discharge machining processes. Int J Adv Manuf Technol 56(1-4): 143-149.

7. Prabhu S, Vinayagam BK (2011) Analysis of surface characteristics of AISI D2 tool steel material using electric discharge machining process with single-wall carbon nanotubes. Int J Machi Machinability Mat (10): 99-119.

8. Boopathi R, Sundaram S, Senthilkumar C, Prabu M, Senthilkumar K, et al. (2015) Investigation on the effect of brass and copper electrodes during electric discharge machining of Inconel 718 using nanoparticles mixed dielectric fluid. J Che Pharm Sci (7): 08-11.

9. Kuppan P, Rajadurai A, Narayana S (2008) Influence of EDM process parameters in deep hole drilling of inconel-718. Int J Manuf Tecnol 38(1-2): 74-84.

10. Boopathi R, Sundaram S, Senthilkumar C, Prabu M, Senthilkumar K (2015) Optimization of EDM parameters for Inconel 718 using response surface methodology. Int J Appl Sci Engg 10(50): 526-529.

11. Uno Y, Okada A, Hayashi Y, Tabuchi YE (1998) Surface integrity in EDM of aluminum bronze with nickel powder mixed fluid. JJpn Soc Elec Mach 32: 24-31.

12. Boopathi R, Sundaram S (2014) Influence of process parameters for electrical discharge machine using nanoparticles and brass electrode. Int J Res Advent Tech 2(11): 45-49.

13. Mai C, Hocheng H, Huang S (2011) Advantages of carbon nanotubes in electrical discharge machining. Int J Adv Manuf Technol 59(1-4): 111117.

14. Prabhu S, Vinayagam BK (2010) Nano surface generation of grinding process using carbon nano tubes. Indian Acad Sci 35(6): 747-760.

15. Montgomery DC (1997) Design and analysis of experiments, ( $4^{\text {th }}$ edn), John Wiley Sons, New York, USA. 
Creative Commons Attribution 4.0 International License

For possible submissions Click Here

\begin{tabular}{|l|} 
RDMS \\
Benefits of Publishing with us \\
- High-level peer review and editorial services \\
- Freely accessible online immediately upon publication \\
- Authors retain the copyright to their work \\
- Licensing it under a Creative Commons license \\
- Visibility through different online platforms
\end{tabular}

